\title{
Effects of 1,3,4-thiadiazine compound with antidepressant properties in ligation model of acute pancreatitis
}

\author{
Alexey Sarapultsev ${ }^{1,2}$, Oleg Chupakhin ${ }^{1,3}$, Maxim Rantsev ${ }^{2}$, Petr Sarapultsev ${ }^{1,2}$, Irina Danilova ${ }^{1,2}$, \\ Svetlana Medvedeva ${ }^{1,2}$, Larisa Sidorova ${ }^{1}$, Tatyana Tseitler ${ }^{1}$, Svetlana Brilliant ${ }^{1,2}$ and Vadim \\ Tseǐlikman ${ }^{4}$ \\ ${ }^{1}$ Ural Federal University Named After the First Pres. of Russ. B.N. Yeltsin, Ekaterinburg, Russian Federation \\ ${ }^{2}$ Institute of Immunology and Physiology of the Ural Branch of the RAS, Ekaterinburg, Russian Federation \\ ${ }^{3}$ The IJ Postovsky Institute of Organic Synthesis of the Ural Branch of the RAS, Ekaterinburg, Russian Federation \\ ${ }^{4}$ South Ural State University, Chelyabinsk, Russian Federation
}

\begin{abstract}
Based on hypotheses concerning the role of stress in acute pancreatitis development, the experimental approach for the decrease stress damage via the use the compound with proven antistress/neuroleptic action was conducted. The study was aimed to discover 2-morpholino5-phenyl-6H-1,3,4-thiadiazine hydrobromide (compound L-17) therapeutic action in experimental acute pancreatitis. The experimental model used was the ligation model. The trial was carried out on 50 male Wistar rats with average body weight $180-240 \mathrm{~g}$. Histological picture of the pancreas was studied and biochemical and enzyme-immunoassays were carried out on the first and seventh days. The significant reduction in mortality on the background of L-17 compound administration was observed. While levels of all cytokines increased in induced experimental acute pancreatitis groups, the cytokine level rise was decreased when compound L-17 was administered. On the cellular level, the study revealed L-17's ability to prevent granulocytosis and decrease granulocytes infiltration to inflammatory foci. The decrease in inflammatory reaction magnitude and prevention of abscess formation in experimental acute pancreatitis accompanied by sistemic inflamamtion was due to L-17's ability to reduce neutrophilia and neutrophil entry into the injury zone.
\end{abstract}

Key words: 1,3,4-thiadiazines - Acute pancreatitis - Antipsychotics - Granulocytes - Neuroleptics - Stress

\section{Introduction}

Acute pancreatitis (AP) caused approximately 275,000 hospitalizations in 2009 (more than a 2 -fold increase since 1982), and it is the single most frequent gastrointestinal cause of hospital admissions in the United States (Peery et al. 2012). The reason for this is its diverse aetiology and the unpredictable course of the disease (Maleszka et al. 2017). The aetiology, pathogenesis, and progression of acute pancreatitis are the subjects of numerous experimental and clinical studies

Correspondence to: Alexey Sarapultsev, Institute of Immunology and Physiology of the Ural Branch of the RAS, 106 Pervomayskaya street, Ekaterinburg, Russian Federation, 620002

E-mail: a.sarapultsev@gmail.com
(Tomaszewska et al. 2000). The aetiology of AP, apart from alcohol abuse and cholelithiasis, may also include a vascular component responsible for pancreatic ischaemia (Tomaszewska et al. 2000). However, the most frequent aetiology is cholelithiasis, which accounts for $30-60 \%$ of cases (Maleszka et al. 2017).

Despite the new understanding and developments in AP diagnosis, aetiology, and early and late management in the past decade, no specific effective treatment has been reported from clinical trials (Ceranowicz et al. 2008; Tenner et al. 2013). The pathophysiology of acute pancreatitis is still based on the 1998 hypothesis of Rinderknecht that the effects occur on distant organs following the release of inflammatory mediators by activated immune cells in response to pancreatic tissue damage (Rinderknecht 1988; Ceranowicz et al. 2007). This pathophysi- 
ological approach suggests that activated leukocytes and the systemic release of cytokines play a key role in the conversion of local pancreatic injury into a systemic process (Banks et al. 1991; Brady et al. 1999). However, later observations that proinflammatory cytokine gene expression is not coupled to a specific form of injury but is instead observed in all forms suggest that those molecules constitute part of an intrinsic or innate stress response system (Mann 2003).

Furthermore, the secretion of TNF- $\alpha$ due to the action of various stressful stimuli has now been demonstrated in many cell types, including pancreatic acinar cells, and direct links between acute/chronic pancreatitis and stress reaction have been described in recent decades (Cosen-Binker et al. 2003, 2004; Binker et al. 2010, 2014). Thus, it has been shown that AP induction following stress is more severe than in its absence and that pancreatitis itself acts as an even stronger and noxious stress generator than long-term animal restraint. Furthermore, Cosen-Binker et al. (2004) maintain that once severe AP is triggered and the inflammatory cascade unchained, added stress is essentially adding more fuel to an already voracious fire'.

With that, an experimental approach for decreased stress damage via the use of anaesthetics has been described (CosenBinker et al. 2003). Treatment with an anaesthetic (lidocaine chlorhydrate) before triggering AP has been shown to decrease the severity of the disease. This was most likely due to the anaesthetic interrupting arc reflexes and rendering milder gastric lesions, and the effect was more pronounced when associated with adrenergic pathway blockage by phentolamine and propranolol antagonists (Cosen-Binker et al. 2003). In a later study of Binker et al. (2010), pancreatitis severity was greatly decreased by treating animals with an anti-TNF- $\alpha$-antibody which diminished all inflammatory parameters, histopathological scores, and apoptotic/necrotic markers in stressed/ cerulein-treated rats. These animals, however, still developed a very mild form of this disease, and the authors concluded that the limited protection achieved in vivo was most likely due to multiple factors involved in pancreatitis development, some of which must act independently of TNF- $\alpha$.

Our previous research revealed that compounds from the substituted 1,3,4-thiadiazines group affect the course of experimental AP (Rantsev et al. 2013). Administration of the tested compounds significantly changed the systemic inflammatory response pattern on the first experimental day, reduced mortality rates and lowered cytokine levels (Rantsev et al. 2013). Similar changes were observed after the administration of these compounds in experimental myocardial infarction (Sarapultsev et al. 2014). The common dominant role of inflammation and stress reaction in both pathogeneses indicates that stress modulation is a key mechanism in 1,3,4-thiadiazine action.

This was confirmed by stress immobilization experiments where the substituted 1,3,4-thiadiazine L-17 lowered reac- tion to stress (Sarapultsev et al. 2015) and by the results of pharmacological evaluation (Sarapultsev et al. 2016). A report demonstrated that L-17 combined adrenergic, cholinergic and serotonin blockers and exerted its best effect in a similar concentration range to that used for the atypical antipsychotic agent Eglonyl (sulpiride) for antidepressants such as amitriptyline and in the alpha-blocker pyrroxanum (Sarapultsev et al. 2016). These promising research results on the course of experimental AP and the ability to lower reaction to stress by the proven antistress/neuroleptic action of this compound have inspired this extended study's aim: to investigate the therapeutic mechanisms of L-17, with a histological, haematological, biochemical and immunohistochemical evaluation and an assessment of circulating cytokine levels.

\section{Material and Methods}

\section{Test compound}

2-morpholino-5-phenyl-6H-1,3,4-thiadiazine hydrobromide (compound L-17) (Reaxys $\mathrm{RN}=14755889$, CAS NUMBER 193208-23-0) from the group of substituted 1,3,4-thiadiazines studied in these experiments has proven a biological effect (Rantsev et al. 2013; Sarapultsev et al. 2014, 2015, 2016). The lethal dose of L-17 (LD50) is $434 \mathrm{mg} /$ $\mathrm{kg}$ (by weight), and the compound is a registered invention (United States Patent No 6313111 of 6 November 2001, PCT RF Patent No 2259371 of 27 August 2005).

\section{Animal preparation}

The experiment was performed on healthy, sexually mature, and nonlinear albino male rats quarantined in the vivarium of the Institute of Immunology and Physiology of the Ural Division of RAS (Ekaterinburg, Russia). The animals showed no symptoms of any disease, and all were kept under the same conditions and fed according to a customary schedule. All experimental procedures with the animals were approved by the Institute of Animal Care and Use Committee at the Institute of Immunology and Physiology of the Ural Division of RAS (pan-1-04-2015) and performed in accordance with Directive 2010/63/EU for the protection of laboratory animals, the APS Guiding Principles in the Care and Use of Vertebrate Animals in Research and Training, and the Laboratory Practice Regulations of RF (Ministry of Public Health Order No. 267 from 19. 06. 2003).

\section{Experimental model of acute pancreatitis}

The experimental model used was described in a previous work (Rantsev et al. 2013) and is relevant to the most 
common clinical form of AP developing in cholelithiasis. According to the literature, experimental models of AP can be divided into in vivo (non-invasive and invasive) and ex vivo models (Ceranowicz et al. 2015). The onset, development, severity and extent of AP as well as the mortality vary considerably between these different models (Ceranowicz et al. 2015). The invasive in vivo ligation model used in a study (Rantsev et al. 2013) causes a clinical syndrome resembling the multiple organ failure observed in humans (pancreatic necrosis and haemorrhage, white cell infiltration and multiple microthrombi (Vasilescu and Tasca 1991) and mimics the acute pancreatitis seen after Polya gastrectomy ( $\mathrm{Su}$ et al. 2006).

Concise description of the technique: under general anaesthetic, a midline $2-3 \mathrm{~cm}$ laparotomy was performed along the Sergeant's white (Hunter's) line to reduce blood loss. The duodenum, mesogaster and part of the stomach were delivered, and transillumination of duodenum mesentery elements was performed to visualize details, including the affected elements (pancreatic gland ducts and duodenum marginal vessel). Isolated ligation of the main pancreatic duct was then performed $0.5 \mathrm{~cm}$ from the duodenum wall. The thickness of the filaments was $8.0(0.040-0.049 \mathrm{~mm})$ on the non-traumatic needle of the circular section. The laparotomy wound was sutured. After the first 24 hours, the animals only received water, and they were switched to habitual eating patterns after 48 hours. Ten minutes after experimental AP modelling, the animals resumed preoperative behavioural reactions. After evaluating behavioural patterns over 24 hours, there were no detectable peculiarities in behavioural responses, and the animals were active and responded readily to photoirritation and acoustic stimulation. There were no symptoms of respiratory failure, malnutrition or altered liquid consumption.

\section{Experimental protocol}

The trial was performed on fifty 8-to-16-week old (mean age) male Wistar rats with an average body weight of 200 $300 \mathrm{~g}$ (Table 1). Animals of the same age provided at the same time by the rat farm formed the trial and the reference sets. The animals were randomly divided into experimental groups to obtain statistically reliable results, and groups A-D were established: (1) Group A comprised 5 intact animals with an average body weight of $274 \mathrm{~g}$; (2) experimental pancreatitis Group B contained 20 animals with an average body weight of $250 \mathrm{~g}$ divided into Groups B1 and B7, marking the day 1 and day 7 end-points of the experiment, with 10 animals in each Group; (3) Group C comprised 5 intact animals with an average body weight of $244 \mathrm{~g}$, and they were injected intraperitoneally with $40 \mathrm{mg} / \mathrm{kg}$ of L-17 compound and (4) Group D comprised 20 animals with induced experimental acute pancreatitis; their average body weight was $256 \mathrm{~g}$, and these animals were injected intraperitoneally with $40 \mathrm{mg} / \mathrm{kg}$ of L-17 compound an hour after surgery. A $40 \mathrm{mg} / \mathrm{kg}$ dose of $\mathrm{L}-17$ compound was then repeatedly injected as often as once every 24 hours. Group D was divided into sub-Groups D1 and D7 to mark experimental-day end-points.

The individual experimental procedure was as follows: after overnight fasting, the rats were anaesthetized with ether, and experimental acute pancreatitis was performed; diazepam $(2.5 \mathrm{mg} / \mathrm{kg})$ was used to reduce the dose of general anaesthetic and for smoother induction and recovery, and all rats were anaesthetized with ether at the experimental endpoints and euthanized.

\section{Histological and laboratory testing}

Blood was collected in at least $5 \mathrm{ml}$ volumes in separate tubes for different studies directly from the abdominal aorta without contact with surrounding tissues.

\section{Biochemistry study}

Biochemical testing was performed by a DU-800 spectrophotometer (Beckman Coulter Int S.A., Switzerland).

For biochemical analysis, $3 \mathrm{ml}$ of blood was obtained from the tail vein for subsequent centrifugation and serum separation. The serum activity of alanine aminotransferase (ALT) and aspartate aminotransferase (AST) was investigated at the endpoints of the experiment (reagent kits ALT 01/11 and AST 01/11, "Vital Development Corporation", Saint- Peters-

Table 1. Experimental protocol

\begin{tabular}{llcc}
\hline Group & Group description & Number of animals & Mortality \\
\hline A & Intact animals & 5 & 0 \\
\hline B-1 & \multirow{2}{*}{ Experimental AP } & 10 & $10 \%$ (1 animal) \\
B-7 & & 10 & $50 \%$ (5 animals) \\
\hline C & L-17 compound administration & 5 & 0 \\
\hline D-1 & \multirow{2}{*}{ Experimental AP + L-17 compound } & 10 & 0 \\
D-7 & & 10 & $30 \%$ (3 animals)
\end{tabular}

AP, acute pancreatitis. 
burg, Russia) using an IM_MAGE 800 Immunochemistry System (Beckman Coulter Int S.A., Switzerland).

Serum bilirubin: the serum total and direct bilirubin were measured according to (Rutkowski and DeBaare 1966). Serum indirect bilirubin was obtained by subtracting the obtained direct bilirubin level from the obtained total bilirubin. The level of creatinine in the serum was measured according to Heinegård and Tiderström (1973).

\section{Immunohistochemical study}

Two millilitre samples of arterial blood were collected and centrifuged for $10 \mathrm{~min}$ at $1,000 \times g$. The plasma portion was collected, and the sample was stored at $-70^{\circ} \mathrm{C}$ until all plasma samples were obtained. ELISA analysis for plasma cytokine levels was performed with commercially available test kits following manufacturer instructions (Rat IL-10 Platinum ELISA BMS629/BMS629TEN, Rat TNF- $\alpha$ Platinum ELISA BMS622/BMS622TWO/BMS622TEN, Rat IL-6 Platinum ELISA BMS625/BMS625TEN, Rat IL-1 $\beta$ Platinum ELISA BMS630/BMS630TEN; Thermo Fisher Scientific Inc., Waltham, MA, U.S.A.). All samples were analysed in duplicate, and ELISA testing was performed by a Personal LAB Adaltis immunoassay analyser (Adaltis S.r.l., Guidonia Montecelio, Italy).

\section{Haematological examination}

All blood samples were taken with plastic test tubes containing K3-EDTA as a coagulant, and peripheral samples from experimental and control Group rats were examined by a Celly 7018 parameter veterinary haematological analyser (Biocode-Hycel, Paris France).

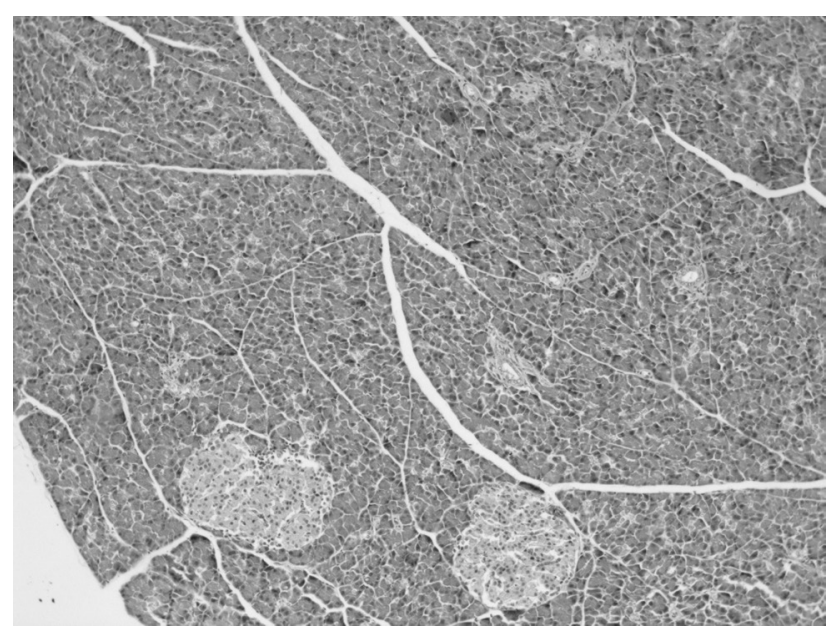

Figure 1. Pancreas of intact animals. (H\&E staining, magnification $\times 200)$.

\section{Histology and morphometric studies}

Material preparation: histological tissue processing was performed with a Leica EG 1160 automatic tissue processor (Leica Mikrosysteme, Nussloach, $\mathrm{GmbH}$ ). The tissue was dehydrated in a series of baths containing increasing concentrations of ethanol, treated with chloroform and embedded in paraffin. The formation of paraffin blocks with tissue samples was conducted using a Leica EG1160 v 4.1 filling station, and 3-5 $\mu \mathrm{m}$-thick histological sections were then cut by a Leica SM2000R sledge.

Analysis of the microscopy samples was performed by Leica DM2500 microscope connected to a Leica DFC420 video recorder and a PC (Leica Mikrosysteme, Wetzlar, Germany). The cells were counted, and the blood vessel diameters were measured by Leica application suite v.4.10.0 image analysis software.

Cellular structures were studied with a microscope objective magnification of 100 in 20 fields of vision followed by re-calculation for $1 \mathrm{~mm}^{2}$. The microcirculatory bloodstream vessel diameter was measured at least 20 separate times for each section. Arithmetic mean values were calculated for the data collected, and this was followed by further statistical analysis. Morphometric studies were performed with Leica application suite v.4.10.0 image analysis software, Leica Microsystems.

\section{Statistical analysis}

Statistical investigation utilized the Student's $t$-test and a nonparametric Mann-Whitney test with the Statistica Six Sigma Release 7 computer program used for data mathematical processing. All data are expressed as the mean $\pm \mathrm{SD}$, with $p=0.05$ considered statistically significant.

\section{Results}

\section{Mortality}

A significant experimental reduction in mortality with administration of L-17 compound was observed (10\% vs. $0 \%$ on the 1 st experimental day and $50 v s$. $30 \%$ on the 7 th day in Groups B and D, respectively), with multiple organ failure as the main cause of death in Group B animals (Table 1).

\section{Macroscopic intra-operative pattern}

Cardinal differences in the macroscopic picture for Groups B-7 and D-7 appeared on the seventh experimental day. Group B-7 animals displayed progressive pancreatic necrosis and suppurative complications, whereas Group D-7 had an aborted inflammatory process with no abdominal cavity 

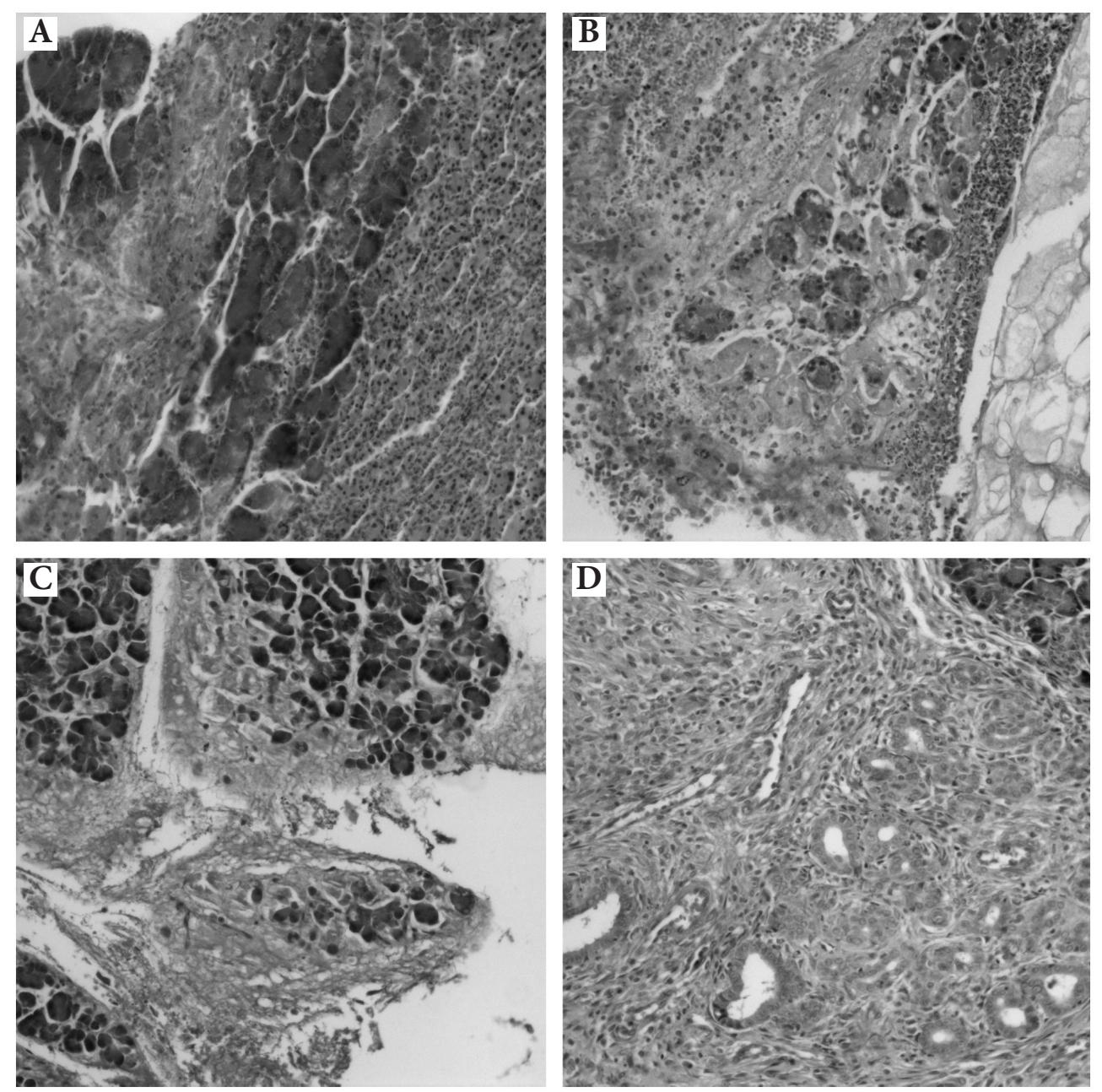

Figure 2. Pancreas of intact animals. A. Group B-1, $1^{\text {st }}$ day. Necrosis of acinar structures of the exocrine part of the pancreas without a pronounced cellular reaction. B. Group D-1, $1^{\text {st }}$ day. Acute pancreattis. 1st day on the background of L-17 compound administation. Necrosis of acinar structures with signs of exudative reaction and diffuse leukocyte infiltration. C. Group B-7, $7^{\text {th }}$ day. Focal necrosis of the acinar structures of the exocrine part of the pancreas, the formation of granulations and the signs of polymorphonuclear leukocytes infiltration and ductal proliferation. D. Group D-7, $7^{\text {th }}$ day. Loose connective tissue with functionally active fibroblasts and a significant number of young collagen fibers. (H\&E staining, magnification $\times 200$ ). effusion and no visual steatonecrosis or fibrinous overlap and with only minor swelling and infiltration noted in the pancreatic tissue.

\section{Microscopic histological intra operative picture}

The microscopic histological intra-operative picture mirrored the observed macropicture.

\section{Microscopic histological intra-operative picture in acute pancreatitis}

The pancreas of Group A animals is presented in Fig. 1. In Group B-1 animals the necrotic foci of destroyed acinar structures in the exocrine part of the gland without a pronounced cellular reaction were observed (Fig. 2. Part 1) while on the 7th day of experimnt focal necrosis of the acinar structures of the exocrine part of the pancreas, the formation of granulations and signs of polymorphonuclear leukocyte infiltration and ductal proliferation were detected (Fig. 2. Part 3).

Microscopic histological intra-operative picture of acute pancreatitis with $L-17$ compound administration

On the 1st day of L-17 compound administration, in animals of D-1 Group signs of acinar structures necrosis with exudative reaction and diffuse leukocyte infiltration were observed (Fig. 2. Part 2). Histological examination of Group D-7 animals revealed the presence of loose connective tissue with functionally active fibroblasts and a significant number of young collagen fibres (Fig. 2. Part 4).

\section{Peripheral blood changes in the animals of the experi- mental group}

The pattern of peripheral blood changes in Group A-D experimental animals is presented in Table 2. 
Table 2. Pattern of peripheral blood changes in animal experimental groups

\begin{tabular}{|c|c|c|c|c|c|c|c|c|}
\hline Group & $\begin{array}{c}\text { Erythrocytes } \\
\left(10^{12} / 1\right)\end{array}$ & $\begin{array}{l}\text { Hemoglobin } \\
(\mathrm{g} / \mathrm{l})\end{array}$ & $\begin{array}{l}\text { Hematocrit } \\
(\%)\end{array}$ & $\begin{array}{l}\text { Leucocytes } \\
\qquad\left(10^{9} / \mathrm{l}\right)\end{array}$ & $\begin{array}{c}\text { Granulocytes } \\
\left(10^{9} / \mathrm{l}\right)\end{array}$ & $\begin{array}{l}\text { Lymphocytes } \\
\left(10^{9} / \mathrm{l}\right)\end{array}$ & $\begin{array}{c}\text { Monocytes } \\
\left(10^{9} / \mathrm{l}\right)\end{array}$ & $\begin{array}{l}\text { Thrombocytes } \\
\left(10^{9} / 1\right)\end{array}$ \\
\hline A & $6.92 \pm 0.5$ & $127.2 \pm 6.84$ & $33.2 \pm 2.72$ & $4.1 \pm 1.43$ & $0.7 \pm 0.35$ & $1.4 \pm 0.7$ & $0.09 \pm 0.04$ & $956.7 \pm 98.7$ \\
\hline C & $6.8 \pm 0.13$ & $132 \pm 3.12$ & $34 \pm 1.2$ & $3.7 \pm 1.0$ & $0.6 \pm 0.4$ & $1.2 \pm 0.6$ & $0.08 \pm 0.05$ & $925 \pm 8.4$ \\
\hline B-1 & $6.84 \pm 0.34$ & $143.33 \pm 4.19^{*}$ & $37.92 \pm 1.58^{*}$ & $2.3 \pm 0.31^{\star, \#}$ & $1.85 \pm 0.64^{*, \#}$ & $0.45 \pm 0.23^{*}$ & $0.09 \pm 0.04^{*}$ & $689.2 \pm 29.28^{\star, \#}$ \\
\hline D-1 & $7.16 \pm 0.78^{*}$ & $135.73 \pm 2.09^{*}$ & $37.57 \pm 4.93$ & $3.65 \pm 1.16$ & $2.57 \pm 0.62$ & $0.92 \pm 0.77$ & $0.13 \pm 0.1$ & $819.21 \pm 65.93^{\star}$ \\
\hline B-7 & $6.21 \pm 0.83$ & $113.67 \pm 9.46$ & $32.17 \pm 2.65^{\#}$ & $9.75 \pm 1.76^{\#}$ & $7.45 \pm 1.67^{\#}$ & $1.86 \pm 0.17$ & $0.44 \pm 0.11^{\#}$ & $1067.5 \pm 318.37$ \\
\hline $\mathrm{D}-7$ & $6.28 \pm 0.58$ & $113.73 \pm 2.28$ & $30.51 \pm 0.92$ & $4.63 \pm 2.78$ & $3.22 \pm 1.64$ & $1.16 \pm 0.9$ & $0.13 \pm 0.09$ & $1097.11 \pm 51.31$ \\
\hline
\end{tabular}

${ }^{*} p<0.05$ the first $v$ s. seventh day; ${ }^{\#} p<0.05$ groups without treatment $v s$. groups with treatment on the same day of the experiment.

\section{Pattern of peripheral blood changes due to AP}

Our results determined an increase in total haemoglobin and the haematocrit index in Group B-1 on the first day of the experiment. Similarly, there was a significant 2.5 -fold increase in granulocyte number and a decrease in leukocytes, lymphocytes and platelets compared with the intact Group A animals, but no changes in monocytes were observed. However, the granulocyte number increased 3-fold (up to $7.45 \pm 1.67$ ) for Group B-7 on the 7 th experimental day together with a significant increase in leucocytes $(9.75$ $\pm 1.76)$, lymphocytes $(1.86 \pm 0.17)$ and blood monocytes $(0.44 \pm 0.11)$.

\section{Pattern of peripheral blood changes due to AP with the administration of $L-17$ compound}

While the administration of L-17 compound to Group $C$ produced no significant peripheral blood changes, the following changes were recorded for Group D1 on the first experimental day: erythropoiesis manifested with increased total erythrocytes and haemoglobin, and there was also a significant increase in total thrombocytes $(689.2 \pm 29.28)$

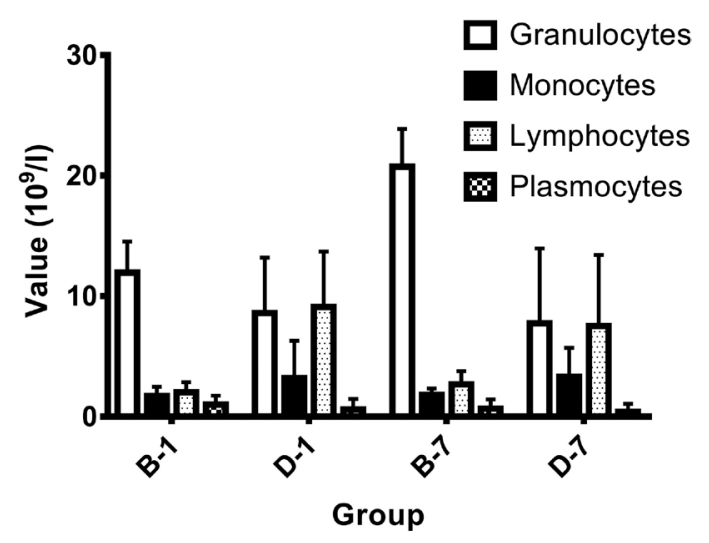

Figure 3. Results of morphometric study of the pancreas. compared with intact animals. However, no significant differences in values were observed on the 7th experimental day for the Group D-1 experimental group with L-17 administration.

Comparison of peripheral blood changes in animals with AP with and without $L-17$ compound administration

(a) Granulocytes: on the first experimental day, the number of granulocytes in Group D-1 blood was significantly higher than in Group B-1 animals, at $2.57 \pm 0.62$ vs. 1.85 \pm 0.64 . While this cell number slightly increased on the 7 th end-point day in experimental pancreatitis animals with L-17 administration, the number increased 3-fold from the first experimental day values to $7.45 \pm 1.67$ in animals lacking L-17 administration.

(b) Lymphocytes: the number of lymphocytes in Group D-1 animals with L-17 administration doubled compared with those in the control group on the first experimental day at $0.92 \pm 0.77 v s .0 .45 \pm 0.23$ ).

(c) Leucoytes: while there was a significant increase in the leucocyte number $(1.86 \pm 0.17)$ in Group B-7 animals over Group B-1 by the 7 th experimental day, both administration groups D-1 and D-7 L-17 recorded no significant changes in that week.

\section{Morphometric study of the pancreas}

No structural changes were detected in the Group A and $C$ pancreas; therefore, the morphometric pancreatic tissue study was limited to experimental Group B and D. This study compared the inflammation severity and the nature of the inflammatory infiltrate in the inflammatory dynamics of experimental pancreatitis; the results are listed in Figure 3.

\section{Pattern of morphometric parameter changes in AP}

The morphometric study revealed that the Group B experimental pancreatitis animals had a significant increase 


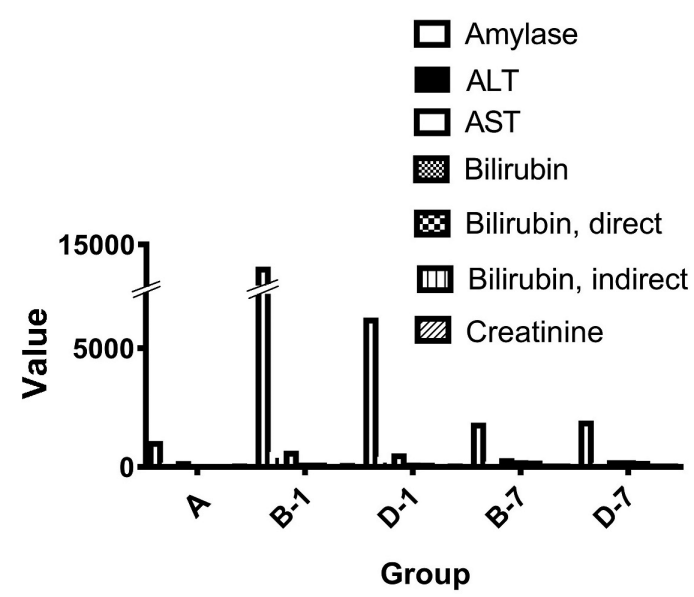

Figure 4. Results of biochemical study. Amylase ALT, AST (U/l); Bilirubin, Creatinine ( $\mathrm{mmol} / \mathrm{l})$.

in granulocyte number in pancreatic tissue on the 7 th experimental day $(20.76 \pm 3.15)$ compared with the first day $(12.96 \pm 3.91)$. While the number of monocytes and lymphocytes did not differ in Groups B-1 and B-7, plasmocytes were significantly lower in Group B-7 on the 7th day of experimental pancreatitis $(0.66 \pm 0.76)$ than in B-1 animals on the first day $(1.0 \pm 0.75)$.

Pattern of changes in morphometric parameters in AP with L-17 compound administration

The morphometric analysis determined no significant changes in quantitative infiltrate composition between the 1 st and 7 th days of the experiment.

Comparison of morphometric parameter changes in animals with AP with and without L-17 compound administration

An important difference occurred in the granulocyte number of the pancreatic tissue of the experimental group on the first experimental day. Here, the granulocyte number for Group D-1 with L-17 administration was significantly lower than in control Group B-1 $(8.6 \pm 4.6$ vs. $12.96 \pm 3.91)$. Moreover, the number of granulocytes on the 7 th experimental day significantly increased compared with the first day in Group B animals with induced acute pancreatitis but no L-17 administration. This indicates increased inflammatory response activity. In addition, Group D animals with L-17 administration had a tendency to decrease granulocytes over time $(7.75 \pm 6.2 v s .8 .6 \pm 4.6)$.

The change in pancreatic monocyte and lymphocyte numbers had a fundamentally different character; the number of monocytes in Group B-1 animals was significantly lower than those in Group D-1 $(1.7 \pm 0.78$ vs. $3.2 \pm 31)$ on the first experimental day, and a similar ratio was maintained on the 7th end-point day in Groups B-7 and D-7 (1.82 \pm 0.53 vs. 3.3 \pm 2.4 ). While similar changes were observed in lymphocyte number at $2.02 \pm 0.84$ vs. $9.1 \pm 4.6$ on the first day and 2.68 \pm 1.09 vs. $7.6 \pm 5.9$ on the seventh day, plasmocyte pancreatic infiltration in B-Groups was significantly higher than in the D-groups at $1.0 \pm 0.75$ vs. $0.6 \pm 087$ on the first day and 0.66 \pm 0.76 vs. $0.4 \pm 0.67$ on the seventh day.

\section{Biochemical study results}

Figure 4 highlights that the most informative biochemical marker reflecting the severity of body reaction to the primary pancreatic lesion was pancreatic amylase, where the blood amylase level was twice high in Group B-1 than in D-1.

\section{Pattern of cytokine response in experimental group animals}

The results of the immunohistochemical study are shown in Figure 5.

\section{Pattern of cytokine response in induced acute pancreatitis}

The results of animals with induced acute pancreatitis on the first day showed a significant increase in circulating cytokine levels; the TNF- $\alpha$ level quadrupled, IL- $1 \beta$ increased 34 times, IL increased 6-11 times and IL-10 increased 373 times compared with intact animals. While the TNF- $\alpha$ levels did not change by the 7 th experimental day, the remaining cytokine levels decreased compared with the first day; IL-1 $\beta$ decreased 5 times $(77.23 \pm 8.5$ in Group B-7 vs. $545.5 \pm 441.2$ in Group B-1), and IL-10 decreased tenfold (66.24 \pm 8.5 in Group B-7 vs. $746.3 \pm 135.9$ in Group B-1).

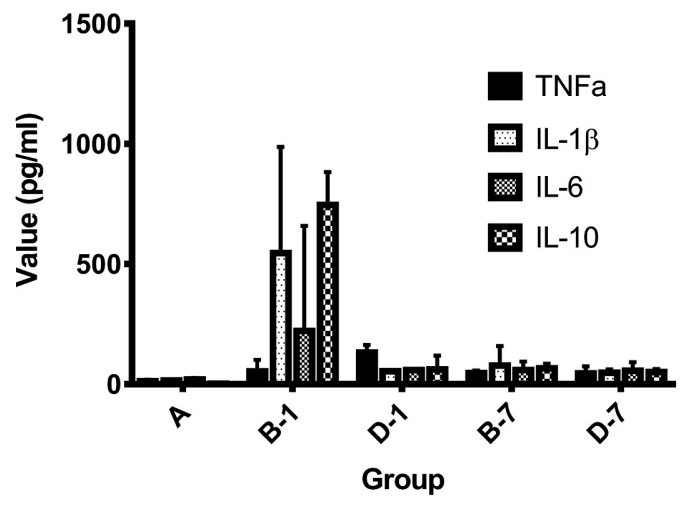

Figure 5. Levels of blood cytokines on the first and seventh day of experiment. 
Cytokine response pattern in AP with compound L-17 administration

A significant increase in cytokine level was noted on the first experimental day for Groups D-1 and D-7 with compound L-17 administration; TNF- $\alpha$ increased 9 times compared with intact animal values (to $131.6 \pm 32.2$ ), the IL- $1 \beta$ and IL-6 tripled $(54.45 \pm 4.1 v s .16 .6 \pm 4.59$ and $58.48 \pm 2.07 v s .19 .67$, respectively), and IL-10 increased 26 times (61.05 \pm 57.34 vs. $2.28 \pm 305$ ). However, by the 7 -day end-point there was a significant increase in the TNF- $\alpha$ level from $44.73 \pm 29.8$ to $131.6 \pm 32.2$, but the remaining cytokine levels did not change from the first day.

Comparison of cytokine response in animals with AP with and without the L-17 compound administration

The results here show that while levels of all cytokines increased in induced experimental acute pancreatitis Groups $\mathrm{B}$ and $\mathrm{D}$, the rise in cytokine level was less than in Group $\mathrm{D}$ when the compound L-17 was administered. In contrast, the reverse situation was observed for TNFa on the first experimental day (53.23 \pm 48.0 in Group B-1 vs. $131.6 \pm 32.2$ in Group D-1).

\section{Reactivity index}

Given the significant fluctuation in the cytokine levels, to understand the meaning of the observed changes, a calculation of the reactivity index (RI) and reactivity coefficient (RC) by E.Yu. Gusev was conducted (Gusev et al. 2008; Zotova et al 2016). The calculation of the RI and RC parameters and their comparison with characteristics of the inflammatory process illustrated that L-17 administration decreased the inflammatory activity from the critical level of systemic inflammation (SI), which is the "prognosis zone" for the development of lethal complications to the conditionally critical level, typical for marginal manifestations of SI or for the hyperactive form of "classical" inflammation (Gusev et al. 2008; Zotova et al 2016).

\section{Discussion}

\section{Changes in cellular content}

\section{Changes in granulocyte number}

The most interesting finding from the comparison of granulocyte number in the experimental Group B and D was the significant increase in granulocytes in animals of Groups $B$ between the 1st and 7th experimental days contrasted with no change in cell number in the L-17-administered animals in this period. This revealed the ability of L-17 to prevent granulocytosis and SI in acute pancreatitis.

A reduction in granulocytosis may prevent SI development as neutrophils can regulate the size and outcome of the inflammatory response through the uptake and release of cytokines and chemokines (Basran et al. 2013). Neutrophils therefore play a significant role in the development of both local and widespread acute pancreatitis (Basran et al. 2013; Williams and Chambers 2014). Moreover, Leppkes et al. (2016) report that intraductal neutrophil-rich aggregates are one of the most important links in local pancreatic inflammation, where their formation and consequent ductal occlusion orchestrates the focal appearance of pancreatitis (Leppkes et al. 2016).

Many authors have described observing a decrease in neutrophil number leading to decreased pancreatitis inflammatory intensity, with reduced pancreatic trypsinactivation peptide and serum amylase levels and the prevention of secondary damage to other organs, including the lungs (Konturek et al. 1998; Frossard et al. 1999; Abdulla et al. 2011). Moreover, Fazal et al. (2000) report that intestinal bacterial translocation is most likely related to increased infiltration of activated neutrophils into intestinal tissue because the release of neutrophil products such as the superoxide anion can cause intestinal damage, whereas neutrophil depletion reduces bacterial translocation. Thus, the ability of L-17 to prevent increased granulocytosis in the blood explains the absence of SI in experimental animals (Group D).

Our results from comparing the granulocyte levels in blood and in the tissue homogenate from pancreatic inflammation foci are therefore of great interest (Figure 3). They revealed that the blood granulocyte levels in Group B-1 animals were lower than in Group D-1 on the first experimental day, but the tissue homogenate granulocyte levels were significantly higher in Group B-1 than in Group D-1. This is explained by the decreased granulocyte infiltration to inflammatory foci following L-17 administration. However, the detected increase in granulocyte numbers in the inflammatory foci in Group B-7 animals on the 7th experimental day and this absence in Group D-7 animals demonstrate the inhibition of a progressive inflammatory reaction by preventing an excessive accumulation of neutrophils in the inflammatory foci.

Data from the literature offer stress reaction development as one reason for the increased neutrophil levels (Bob et al. 2010), and Engler et al. (2004) report that recurrent exposure to the stressor was associated with cell mobilization and increased myelopoiesis in bone marrow. This is paralleled by neutrophil and monocyte accumulation in the circulation and spleen (Engler et al. 2004). Moreover, a stress-induced rise in plasma corticosterone levels leads to an increased release of polymorphonuclear leukocytes from the bone 
marrow, with an accompanying delay in their apoptosis and a significant decrease in numbers and percentages of lymphocytes (Nakagawa et al. 1998).

Stress also induces endotoxaemia in tissue injuries primarily by increasing the intestinal barrier (de Punder and Pruimboom 2015). Bacterial toxins (LPS) that enter the bloodstream, in turn, stimulate neutrophilia (Yakovlev 2003).

The proven ability of thiadiazine compounds such as L-17 to increase resistance to stress (Sarapultsev et al. 2015) explains the observed decrease in neutrophilia and neutrophil count in inflammatory foci and the revealed inhibition of SI.

\section{Changes in leucocyte and monocyte numbers}

The principal difference in lymphocyte and monocyte numbers in experimental Group B and D animal blood and tissue requires explanation. Despite the significant increase in Group B-7 blood monocytes, the infiltration of monocytes in the pancreatic tissue of Group B-1 and B-7 animals was significantly lower than in the D-Groups throughout the experiment (Figure 3). Here, the observed increase in monocytes/macrophages in inflammation foci in L-17-administered animals undoubtedly decreased the magnitude of the inflammatory process and accelerated the onset of granulation formation because macrophages regulate all phases of wound healing and their major function is the absorption of apoptotic and necrotic cells in damaged tissue (Sindrilaru and Scharffetter-Kochanek 2013). Yeager et al. (2016) report that all of the described processes of tissue infiltration by neutrophils, their replacement by macrophages and macrophage differentiation are directly or indirectly regulated by glucocorticosteroids, and stress or almost any other threat to homeostasis causes increased plasma glucocorticoid levels (Yeager et al. 2016). Thus, the early increase in macrophage number in inflammatory foci in animals administered L-17 compound has the following effects: it is not only responsible for a reduction in the magnitude of the inflammatory reaction, as reduced macrophage infiltration causes delayed wound healing (van Amerongen et al. 2007; Mirza et al. 2009), but it is also an indirect sign of the changes that substituted thiadiazines induce in the stress response.

In addition, the increased circulating monocytes in Group B animal blood appears to be responsible for the generalization of inflammation processes because systemic inflammatory events in the early stages of acute pancreatitis are triggered by the activation of circulating monocytes but not T-cells, playing a central role (de Dios et al. 2002).

The significant difference in lymphocyte numbers in the blood and pancreas of experimental animals deserves special attention. Our results highlight that the number of lymphocytes in experimental Group B-1 blood on the first day did not differ from Group D-1 values in these first-day experi- mental animals administered with L-17. However, on the 7 th experimental day, blood lymphocytes significantly increased in Group B-7 animals but did not differ in Group D-7, and the tissue-infiltrating lymphocytes in Groups B-1 and B-7 animals did not change during experimental progression but were significantly lower than in Groups D-1 and D-7.

The more rapid injury zone granulation and lack of purulent foci in L-17-administered D-1 and D-7 animals compared to those in Group B is explained by the different lymphocyte action mechanisms in blood and the injury area.

Figure 3 highlights that the significantly lower plasmocyte infiltration in inflammatory foci in Group D-1 compared with Group B-1 could quite well be beneficial. It is very important that plasmocytes can modulate immune and inflammatory responses, not only by antibody production but also by their secretion of the TNF- $a$ key inflammatory mediator. The resultant accumulation of plasma cells at inflamed sites may therefore promote a synchronized inflammatory process leading to the accumulation of extraordinary levels of locally produced, specific antibodies for certain antigens (Mallison et al. 1991). Hence, the significant decrease in plasmocyte infiltration of the inflammatory focus observed in Group D animals on the first day contributes to decreased severity of the inflammatory reaction.

\section{Cytokines}

A significant increase in circulating cytokine level in B-1 animals was observed over the course of the experimental pancreatic necrosis compared with the normal values (Figure 5). The TNF- $\alpha$ increased 4 -fold, IL-1 $\beta$ increased 34-fold, IL-6 increased 11-fold and IL-10 increased up to 373 times. This is typical in acute pancreatitis development, and it is described in both experimental studies (Dembinski et al. 2001; Ramudo et al. 2005; Zaheer and Zaheer 2005; Ceranowicz et al. 2008; Vinnik et al. 2011)and in clinical studies (Chen et al. 1999; Hirota et al. 2000). Moreover, high levels of interleukins can impede wound repair (Eming et al. 2007); therefore, the decrease in cytokine levels with the increased macrophage number accelerating repair processes (Ceranowicz et al. 2008) observed in the study might be beneficial.

\section{Mortality and systemic inflammation}

SI development in the Group B and D experimental animals was confirmed by the significant increase in cytokine levels on the first experimental day (Bone et al. 1997; Norman 1998). Signs of MODS (multiple organ dysfunction syndrome) and CARS (compensatory anti-inflammatory response syndrome) manifested in B-7 animals on the 7th experimental day as diffuse leukocyte infiltration and abscess formation in the mesen- 
tery and peritoneum and in the appearance of steatonecrotic foci in the pancreatic tissue and accompanying peritonitis.

The ability of L-17 compound to reduce inflammatory cytokine levels may explain the significant experimental reduction in mortality. Here, cytokine levels regulating inflammation reflected the intensity of surgical stress, as in (Aosasa et al. 53). These levels consequently reflect the degree of SI influence on damage to the cells of internal organs, such as the pancreas. Therefore, the decreased IL-10 in Group D animals influenced CARS development, and this was confirmed by the absence of purulent foci and peritonitis on the 7 th day.

A summary of our results (Figure 6) provides the conclusion that the decrease in inflammatory reaction magnitude and prevention of abscess formation and peritonitis in experimental AP accompanied by SI was due to the ability of L-17 to reduce neutrophilia and neutrophil entry into the injury zone. Moreover, the accelerated regeneration was caused by the compound's induced increase in macrophage and lymphocyte numbers in the damaged area. These mechanisms were mediated by the reduction of proinflammatory and anti-inflammatory interleukin levels by L-17. However, increased interleukins and neutrophilia depend on the severity of stress in tissue damage; hence, it is assumed that the major action mechanism of L-17 is anti-stress activity as previously described in the stress immobilization model (Sarapultsev et al. 2015).

\section{Proposed mechanisms of action}

The ability of substituted 1,3,4-thiadiazine compounds to lower stress reaction was previously described (Sarapultsev et al. 2015), and their ability to act on both serotonin and adrenergic systems has been proposed (Sarapultsev et al. 2016).. Here, a singular synchronized-action on serotonergic and adrenergic systems, also seen in psychotropic drugs, significantly enhanced their therapeutic effect (Arnsten 2004) because alpha-1 and serotonin (5HT2A) receptors are involved in the common phosphatidyl inositol/protein kinase C intracellular pathway via Gq proteins (Duman and Nestler 1995).

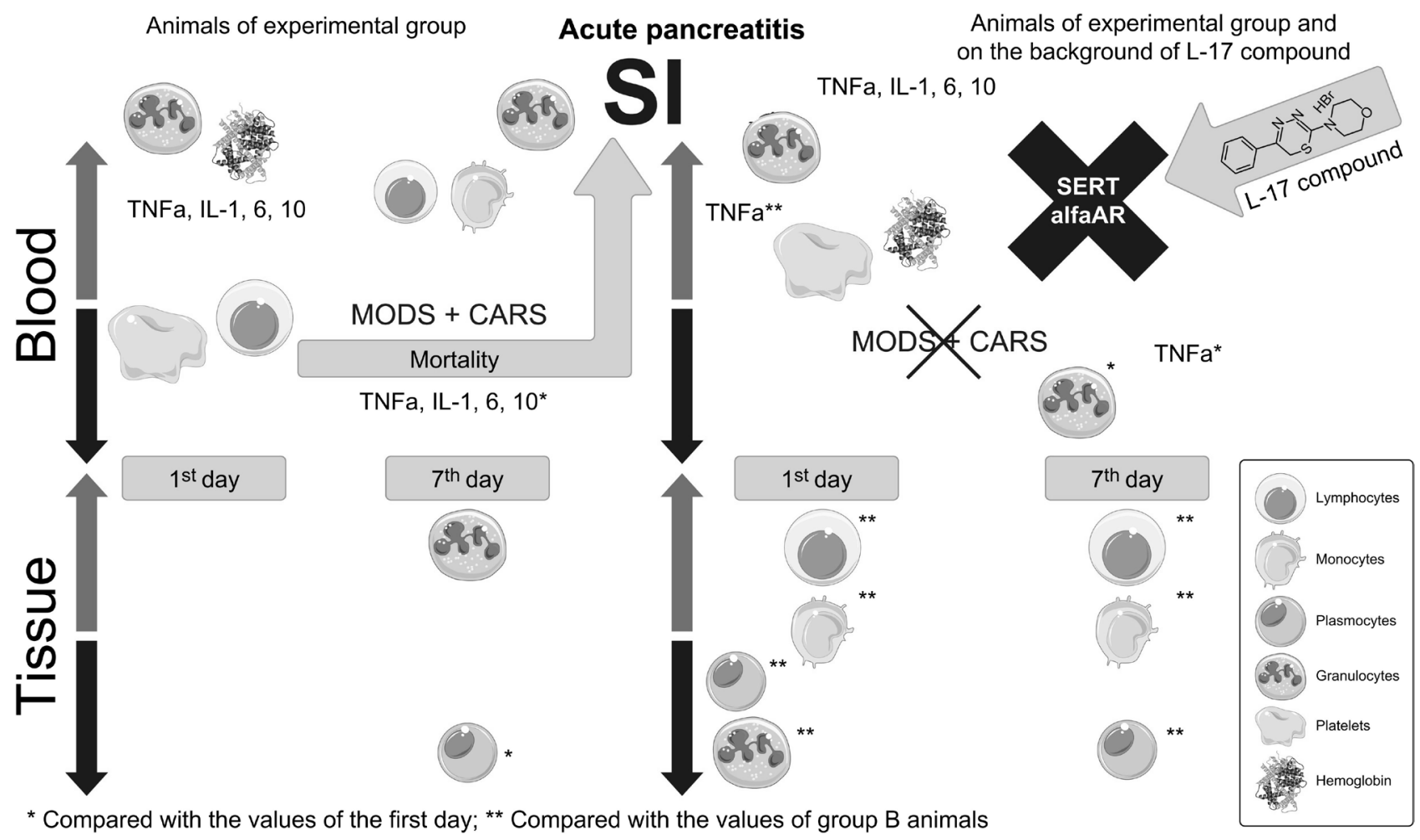

Figure 6. The schematic representation of the L-17 compound effects in experimental acute pancreatitis. On the left part of the picture, the changes in the pancreatic tissue and the blood on the course of experimental acute pancreatitis are described: the rise of cytokines levels which led to the SI development and granulocytosis in the blood (accompanied with the increase in granulocyte numbers in the inflammatory foci on the 7th experimental day), which led to MODS, and CARS manifestation. On the right part of the picture, the changes in the pancreatic tissue and the blood on the background of L-17 compound administration are described: the increase in the lymphocyte and monocyte and the decrease in granulocyte numbers in the tissue on the 1 st day. The decrease in the circulating cytokine levels on the 7th day with no signs of MODS and CARS. 
The described action mechanisms of L-17 are similar in effect to atypical antipsychotics (Sarapultsev et al. 2016), and this could explain its action on both the immune system and inflammatory response. The literature records that antidepressant drugs frequently affect the dysregulated immune response in depressed patients, mainly by improving the serum cytokine profile during therapy (Kenis and Maes 2002; Janssen et al. 2010; Hannestad et al. 2011); this may result from their influence on cytokine release (Kubera et al. 2001a, 2001b, 2005).

The change in monocyte numbers in tissues and blood from the administration of L-17 compound described in this article does not contradict the literature data which showed that antidepressant drugs modulate the peripheral humoral and cell-mediated immune responses through their action on lymphocytes and macrophages (reviewed in 62) (Maes 2011). Recent studies by Nazimek et al. $(2016,2017)$ also highlighted the direct impact of various antidepressant drugs on macrophages and showed that the administration of some antidepressants, including fluoxetine, venlafaxine and moclobemide, resulted in the suppression of humoral and cell-mediated immunity, with a reduction in the release of macrophage proinflammatory mediators and expression of antigen-presentation markers.

In general, compounds with similar biological effects to those used as antidepressants can down-regulate secretion of proinflammatory cytokines and up-regulate the release of anti-inflammatory cytokines. Nazimek et al. (2016) consider this a mechanism of their anti-inflammatory effect (Nazimek et al. 2016, 2017), and it is also well described in the literature (Janssen et al. 2010; Kubera et al. 2011). Moreover, due to their impact on serotonin turnover, antidepressants may alter the immune response at the early stage of cell recruitment to the inflammation site which depends, among other things, on platelet-derived serotonin (Nazimek et al. 2016, 2017). This then decreases the neutrophil infiltration by the administration of L-17 compound described in the present study.

\section{Conclusion}

Given the data from the literature showing that the administration of antidepressant compounds to healthy people can modulate humoral and cell-mediated immune response and improve the course of a number of pathologies such as rheumatoid arthritis and encephalomyelitis on the one hand and the role of stress reaction in the pathogenesis of various diseases on the other, it is possible to cite Nazimek et al. (2016): "treatments with different antidepressant drugs possess significant translational potential and indicate that these drugs could be considered for application in complex therapeutic strategies dedicated to various disease".
Acknowledgments. The authors would like to thank Raymond Marshall and Elsevier Language Editing Services for the help with the language-editing of the manuscript.

Funding information. Partly the study was supported by the Act 211 of the Government of Russian Federation, contract No 02.A03.21.0006; Government contract of Russian Federation with Institute of Immunology and Physiology (AAAAA18-118020690020-1) and the Ministry of Education and Science of the Russian Federation (\# 17.7255.2017/8.9).

Conflict of interest. None.

\section{References}

Abdulla A, Awla D, Thorlacius H, Regnér S (2011): Role of neutrophils in the activation of trypsinogen in severe acute pancreatitis. J. Leukoc. Biol. 90, 975-982

https://doi.org/10.1189/jlb.0411195

Aosasa S, Ono S, Mochizuki H, Tsujimoto H, Osada SI, Takayama E, Seki S, Hiraide H (2000): Activation of monocytes and endothelial cells depends on the severity of surgical stress. World J. Surg. 24, 10-16 https://doi.org/10.1007/s002689910003

Arnsten AF (2004): Adrenergic targets for the treatment of cognitive deficits in schizophrenia. Psychopharmacology $\mathbf{1 7 4}, 25-31$ https://doi.org/10.1007/s00213-003-1724-3

Banks RE, Evans SW, Alexander D, McMahon MJ, Whicher JT (1991): Is fatal pancreatitis a consequence of excessive leukocyte stimulation? The role of tumor necrosis factor $\alpha$. Cytokine 3, $12-16$ https://doi.org/10.1016/1043-4666(91)90004-W

Basran A, Jabeen M, Bingle L, Stokes CA, Dockrell DH, Whyte MK, Walmsley SR, Higgins KR, Vogel SN, Wilson HL, et al. (2013): Roles of neutrophils in the regulation of the extent of human inflammation through delivery of IL-1 and clearance of chemokines. J. Leukoc. Biol. 93, 7-19 https://doi.org/10.1189/jlb.0512250

Binker MG, Binker-Cosen AA, Richards D, Gaisano HY, de Cosen RH, Cosen-Binker LI (2010): Chronic stress sensitizes rats to pancreatitis induced by cerulein: role of TNF-a. World J. Gastroenterol. 16, 5565 https://doi.org/10.3748/wjg.v16.i44.5565

Binker MG, Cosen-Binker LI (2014): Acute pancreatitis: the stress factor. World J. Gastroenterol. 20, 5801 https://doi.org/10.3748/wjg.v20.i19.5801

Bob P, Raboch J, Maes M, Susta M, Pavlat J, Jasova D, Vevera J, Uhrova J, Benakova H, Zima T (2010): Depression, traumatic stress and interleukin-6. J. Affect. Disord. 120, 231-234 https://doi.org/10.1016/j.jad.2009.03.017

Bone RC, Grodzin CJ, Balk RA (1997): Sepsis: a new hypothesis for pathogenesis of the disease process. Chest 112, 235-244 https://doi.org/10.1378/chest.112.1.235

Brady M, Christmas S, Sutton R, Neoptolemos J, Slavin J (1999): Cytokines and acute pancreatitis. Best Pract. Res. Clin. Gastroenterol. 13, 265-289 
https://doi.org/10.1053/bega.1999.0024

Ceranowicz P, Cieszkowski J, Warzecha Z, Dembiński A (2015): Experimental models of acute pancreatitis. Postepy Hig. Med. Dosw. 21, 264-269 (in Polish) https://doi.org/10.5604/17322693.1141101

Ceranowicz P, Cieszkowski J, Warzecha Z, Kuśnierz-Cabala B, Dembiński A (2015): The beginnings of pancreatology as a field of experimental and clinical medicine. Biomed. Res. Int. 128095 https://doi.org/10.1155/2015/128095

Ceranowicz P, Dembinski A, Warzecha Z, Dembinski M, Cieszkowski J, Rembisz K, Konturek S.J, Kusnierz-Cabala B, Tomaszewska R, Pawlik WW (2008): Protective and therapeutic effect of heparin in acute pancreatitis. J. Physiol. Pharmacol. 59 (Suppl 4), 103-125

Chen CC, Wang SS, Lee FY, Chang FY, Lee SD (1999): Proinflammatory cytokines in early assessment of the prognosis of acute pancreatitis. Am. J. Gastroenterol. 94, 213-218 https://doi.org/10.1111/j.1572-0241.1999.00709.x

Cosen-Binker LI, Binker MG, Negri G, Tiscornia O (2003): Acute pancreatitis possible initial triggering mechanism and prophylaxis. Pancreatology 3, 445-456 https://doi.org/10.1159/000074972

Cosen-Binker LI, Binker MG, Negri G, Tiscornia, O (2004): Influence of stress in acute pancreatitis and correlation with stressinduced gastric ulcer. Pancreatology 4, 470-484 https://doi.org/10.1159/000079956

de Dios I, Perez M, de La Mano A, Sevillano S, Orfao A, Ramudo L, Manso MA (2002): Contribution of circulating leukocytes to cytokine production in pancreatic duct obstruction-induced acute pancreatitis in rats. Cytokine 20, 295-303 https://doi.org/10.1006/cyto.2002.2011

de Punder K, Pruimboom L (2015): Stress induces endotoxemia and low-grade inflammation by increasing barrier permeability. Front. Immunol. 6, 223 https://doi.org/10.3389/fimmu.2015.00223

Dembinski A, Warzecha Z, Ceranowicz P, Stachura J, Tomaszewska R, Konturek SJ, Sendur R, Dembiński M, Pawlik WW (2001): Pancreatic damage and regeneration in the course of ischemia-reperfusion induced pancreatitis in rats. J. Physiol. Pharmacol. 52, 221-235

Duman RS, Nestler EJ (1995): Signal transduction pathways for catecholamine receptors. In: Psychopharmacology: Fourth Generation of Progress. (Eds. F.E. Bloom and D.J. Kupfer), pp. 303-320, Raven Press, New York

Eming SA, Werner S, Bugnon P, Wickenhauser C, Siewe L, Utermöhlen O, Davidson JM, Krieg T, Roers A (2007): Accelerated wound closure in mice deficient for interleukin-10. Am. J. Pathol. 170, 188-202

https://doi.org/10.2353/ajpath.2007.060370

Engler H, Bailey MT, Engler A, Sheridan JF (2004): Effects of repeated social stress on leukocyte distribution in bone marrow, peripheral blood and spleen. J. Neuroimmunol. 148, 106-115 https://doi.org/10.1016/j.jneuroim.2003.11.011

Fazal N, Shamim M, Khan SS, Gamelli RL, Sayeed MM (2000): Neutrophil depletion in rats reduces burn-injury induced intestinal bacterial translocation. Crit. Care Med. 28, 1550-1555 https://doi.org/10.1097/00003246-200005000-00048

Frossard JL, Saluja A, Bhagat L, Lee HS, Bhatia M, Hofbauer B, Steer, ML (1999): The role of intercellular adhesion molecule 1 and neutrophils in acute pancreatitis and pancreatitis-associated lung injury. Gastroenterology 116, 694-701 https://doi.org/10.1016/S0016-5085(99)70192-7

Gusev EY, Yurchenko LN, Chereshnev VA, Zotova NV (2008): Methodology of research in systemic inflammation. Tsitokiny i vospalenie 7, 15-23 (in Russion)

Hannestad J, DellaGioia N, Bloch M (2011): The effect of antidepressant medication treatment on serum levels of inflammatory cytokines: a meta-analysis. Neuropsychopharmacology 36, 2452

https://doi.org/10.1038/npp.2011.132

Heinegård D, Tiderström G (1973): Determination of serum creatinine by a direct colorimetric method. Clin. Chim. Acta. 43, 305-310 https://doi.org/10.1016/0009-8981(73)90466-X

Hirota M, Nozawa F, Okabe A, Shibata M, Beppu T, Shimada S, Egami H, Yamaguchi Y, Ikei S, Okajima T, et al. (2000): Relationship between plasma cytokine concentration and multiple organ failure in patients with acute pancreatitis. Pancreas 21, 141-146 https://doi.org/10.1097/00006676-200008000-00006

Janssen DG, Caniato RN, Verster JC, Baune BT (2010): A psychoneuroimmunological review on cytokines involved in antidepressant treatment response. Hum. Psychopharmacol. Clin. Exp. 25, 201-215

https://doi.org/10.1002/hup.1103

Kenis G, Maes M (2002): Effects of antidepressants on the production of cytokines. Int. J. Neuropsychopharmacol. $5,401-412$ https://doi.org/10.1017/S1461145702003164

Konturek PC, Dembinski A, Warzecha Z, Ihlm A, Ceranowicz P, Konturek SJ, Stachura J, Hahn EG (1998): Comparison of epidermal growth factor and transforminggrowth factor- $\beta 1$ expression in hormone-induced acute pancreatitis in rats. Digestion 59, 110-119 https://doi.org/10.1159/000007483

Kubera M, Lin AH, Kenis G, Bosmans E, van Bockstaele D, Maes M (2001): Anti-inflammatory effects of antidepressants through suppression of the interferon- $\gamma /$ interleukin-10 production ratio. J. Clin. Psychopharmacol. 21, 199-206 https://doi.org/10.1097/00004714-200104000-00012

Kubera M, Maes M, Holan V, Basta-Kaim A, Roman A, Shani J (2001): Prolonged desipramine treatment increases the production of interleukin-10, an anti-inflammatory cytokine, in C57BL/6 mice subjected to the chronic mild stress model of depression. J. Affect. Disord. 63, 171-178 https://doi.org/10.1016/S0165-0327(00)00182-8

Kubera M, Maes M, Kenis G, Kim Y. K, Lasoń W (2005): Effects of serotonin and serotonergic agonists and antagonists on the production of tumor necrosis factor $a$ and interleukin-6. Psychiatry Res. 134, 251-258 https://doi.org/10.1016/j.psychres.2004.01.014

Leppkes M, Maueröder C, Hirth S, Nowecki S, Günther C, Billmeier U, Paulus S, Biermann M, Munoz L.E, Hoffmann M, et al. (2016): Externalized decondensed neutrophil chromatin oc- 
cludes pancreatic ducts and drives pancreatitis. Nat. Commun. 7, 10973 https://doi.org/10.1038/ncomms10973

Maes M (2011): Depression is an inflammatory disease, but cell-mediated immune activation is the key component of depression. Prog. Neuropsychopharmacol. Biol. Psychiatry 35, 664-675 https://doi.org/10.1016/j.pnpbp.2010.06.014

Maleszka A, Dumnicka P, Matuszyk A, Pędziwiatr M, MazurLaskowska M, Sporek M, Ceranowicz P, Olszanecki R, Kuźniewski M, Kuśnierz-Cabala B (2017): The Diagnostic usefulness of serum total bile acid concentrations in the early phase of acute pancreatitis of varied etiologies. Int. J. Mol. Sci. 18, 106

https://doi.org/10.3390/ijms18010106

Mallison SM, Smith JP, Schenkein HA, Tew JG (1991): Accumulation of plasma cells in inflamed sites: effects of antigen, nonspecific microbial activators, and chronic inflammation. Infect. Immun. 59, 4019-4025

Mann DL (2003): Stress-activated cytokines and the heart: from adaptation to maladaptation. Annu. Rev. Physiol. 65, 81-101 https://doi.org/10.1146/annurev.physiol.65.092101.142249

Mirza R, DiPietro LA, Koh TJ (2009): Selective and specific macrophage ablation is detrimental to wound healing in mice. Am. J. Pathol. 175, 2454-2462 https://doi.org/10.2353/ajpath.2009.090248

Nakagawa M, Terashima T, D'yachkova Y, Bondy GP, Hogg JC, van Eeden SF (1998): Glucocorticoid-induced granulocytosis. Circulation 98, 2307-2313

https://doi.org/10.1161/01.CIR.98.21.2307

Nazimek K, Kozlowski M, Bryniarski P, Strobel S, Bryk A, Myszka M, Tyszka A, Kuszmiersz P, Nowakowski J, FilipczakBryniarska I (2016): Repeatedly administered antidepressant drugs modulate humoral and cellular immune response in mice through action on macrophages. Exp. Biol. Med. 241, $1540-1550$ https://doi.org/10.1177/1535370216643769

Nazimek K, Strobel S, Bryniarski P, Kozlowski M, FilipczakBryniarska I, Bryniarski K (2017): The role of macrophages in anti-inflammatory activity of antidepressant drugs. Immunobiology 222, 823-830

https://doi.org/10.1016/j.imbio.2016.07.001

Norman J (1998): The role of cytokines in the pathogenesis of acute pancreatitis. Am. J. Surg. 175, 76-83 https://doi.org/10.1016/S0002-9610(97)00240-7

Peery AF, Dellon ES, Lund J, Crockett SD, McGowan CE, Bulsiewicz WJ, Gangarosa LM, Thiny MT, Stizenberg K, Morgan DR, et al. (2012): Burden of gastrointestinal disease in the United States: 2012 update. Gastroenterology 143, 1179-1187 https://doi.org/10.1053/j.gastro.2012.08.002

Ramudo L, Manso M. A, Sevillano S, de Dios I (2005): Kinetic study of TNF- $\alpha$ production and its regulatory mechanisms in acinar cells during acute pancreatitis induced by bile-pancreatic duct obstruction. J. Pathol. 206, 9-16 https://doi.org/10.1002/path.1747

Rantsev MA, Sarapultsev PA, Chupakhin ON, Sarapultsev AP, Khodakov VV, Danilova IG (2013): The treatment of focal and extensive pancreonecrosis in the experiment. Med. Almanac. 5, 92-94 (in Russian)
Rinderknecht H (1988): Fatal pancreatitis, a consequence of excessive leukocyte stimulation? Int. J. Pancreatol. 3, 105-112

Rutkowski RB, Debaare L (1966): An ultramicro colorimetric method for determination of total and direct serum bilirubin. Clin. Chem. 12, 432-438

Sarapultsev AP, Chupakhin ON, Sarapultsev PA, Rantsev MA, Medvedeva SU, Sidorova LP, Abidov MT, Danilova IG (2014): Modulation of inflammatory response improves myocardial infarct healing in rats. Curr. Pharm. Des. 20, 1980-1986

https://doi.org/10.2174/13816128113199990492

Sarapultsev AP, Chupakhin ON, Sarapultsev PA, Sidorova LP, Tseitler TA (2016): Pharmacologic evaluation of antidepressant activity and synthesis of 2-morpholino-5-phenyl-6h-1, 3, 4-thiadiazine hydrobromide. Pharmaceuticals 9, 27 https://doi.org/10.3390/ph9020027

Sarapultsev PA, Chupakhin ON, Medvedeva SU, Mukhlynina EA, Brilliant SA, Sidorova LP, Danilova IG, Sarapultsev AP (2015): The impact of immunomodulator compound from the group of substituted thiadiazines on the course of stress reaction. Int. Immunopharmacol. 25, 440-449 https://doi.org/10.1016/j.intimp.2015.02.024

Sindrilaru A, Scharffetter-Kochanek K (2013): Disclosure of the culprits: Macrophages-Versatile regulators of wound healing. Adv. Wound Care (New Rochelle) 2, 357-368 https://doi.org/10.1089/wound.2012.0407

Su K, Cuthbertson C, Christophi C (2006): Review of experimental animal models of acute pancreatitis. HPB (Oxford) 8, 264-26 https://doi.org/10.1080/13651820500467358

Tenner S, Baillie J, DeWitt J, Vege SS (2013): American College of Gastroenterology guideline: management of acute pancreatitis. Am. J. Gastroenterol. 108, 1400 https://doi.org/10.1038/ajg.2013.218

Tomaszewska R, Dembiński A, Warzecha Z, Ceranowicz P, Stachura $J$ (2000): Morphological changes and morphological-functional correlations in acute experimental ischemia/reperfusion pancreatitis in rats. Pol. J. Pathol. 51, 179-184

van Amerongen MJ, Harmsen MC, van Rooijen N, Petersen AH, van Luyn MJ (2007): Macrophage depletion impairs wound healing and increases left ventricular remodeling after myocardial injury in mice. Am. J. Pathol. 170, 818-829 https://doi.org/10.2353/ajpath.2007.060547

Vasilescu C, Tasca C (1991): Acute experimental pancreatitismorphological evidence for the development of a multiple organ failure syndrome. Rom. J. Morphol. Embryol. 37, 25-29

Vinnik YuS, Cherdantsev DV, Salmina AB, Markelova NM, Miller MS (2011): Features of the regulation of apoptosis of immunocompetent blood cells in acute destructive pancreatitis. Novosti Khirurgii 19, 37-42 (in Russian)

Williams AE, Chambers RC (2014): The mercurial nature of neutrophils: still an enigma in ARDS? Am. J. Physiol. Lung. Cell. Mol. Physiol. 306, L217-230 https://doi.org/10.1152/ajplung.00311.2013

Yakovlev MY (2003): Elements of the endotoxin theory of human physiology and pathology. Hum. Physiol. 29, 476-486 https://doi.org/10.1023/A:1024989709554 
Yeager MP, Pioli PA, Collins J, Barr F, Metzler S, Sites BD, Guyre PM (2016): Glucocorticoids enhance the in vivo migratory response of human monocytes. Brain Behav. Immun. 54, 86-94 https://doi.org/10.1016/j.bbi.2016.01.004

Zaheer S, Zaheer A (2005): Bile-pancreatic juice exclusion increases p38MAPK activation and TNF- $\alpha$ production in ligationinduced acute pancreatitis in rats. Pancreatology 5, 20-26 https://doi.org/10.1159/000084486
Zotova NV, Chereshnev VA, Gusev EY (2016): Systemic inflammation: methodological approaches to identification of the common pathological process. PloS One, 11, e0155138 https://doi.org/10.1371/journal.pone.0155138

Received: September 20, 2017

Final version accepted: March 29, 2018

First published online: July 26, 2018 